and their evolution since, the programs' main characteristics and approaches, as well as the tensions which exist between the universities' goals and those of other aid actors, and the role that the government should play in this area. It is organized in several chapters including a more detailed study of various programs and final reflections which should contribute to improving training for development in Spain.

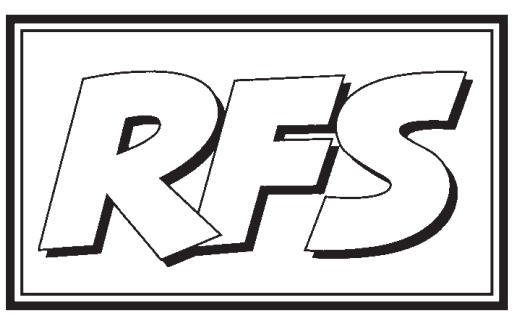

Revista de Fomento Social, 59 (2004), 239-276

\section{La enseñanza de la religión en la escuela. Una solución posible}

\author{
Consejo de Redacción
}

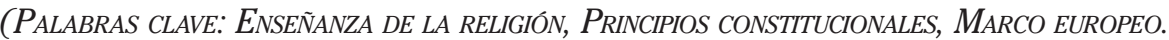
KEY WORDS: TEACHING OF RELIGION, CONSTITUTIONAL PRINCIPLES, EUROPEAN FRAMEWORK)

¿Qué reformas necesita nuestro sistema educativo? Entre éstas, ¿se encuentra la de la enseñanza de la religión? En el otoño de 2004 nuestra sociedad se hace esa pregunta. Esta cuestión forma parte de las que se va a plantear con el debate social a que nos convoca la ministra de Educación. Es también nuestra pregunta. Nosotros creemos que, entre las reformas educativas necesarias en la sociedad española, está la enseñanza escolar de la religión. No es la cuestión esencial ni la más urgente, pero no cabe duda de que hay un problema escolar con este nombre, que se magnifica en el debate público y mediático. La solución que le dio la LOGSE ${ }^{1}$ en octubre de 1990 no nos parece una buena respuesta a este problema, que atraviesa nuestra reciente historia. Tampoco

1 Ley orgánica 1/1990 de 3 de octubre, de ordenación general del sistema educativo. BOE, 4-10-1990. 
nos lo parece la que propuso la $\mathrm{LOCE}^{2}$ (ahora paralizada), en diciembre de 2002. No quisiéramos que en los próximos decenios ésta siguiese siendo una cuestión lastrada, sino que esperamos que se abran prudentemente caminos para su solución. Por eso queremos contribuir con este editorial a pensar una posible solución.

La enseñanza de la religión en la escuela es un asunto que periódicamente ocupa a la opinión pública. En él hay diferentes posiciones en juego, tanto las más circunstanciales como las más duraderas, perspectivas que se van cerrando, junto a otras nuevas que se abren. Debajo de una permanente, pero tal vez falsa, actualidad, parece que los argumentos están enquistados en posiciones ideológicas muy cerradas. Esta cuestión escolar plantea, si la miramos en una perspectiva más amplia, también interrogantes importantes para el conjunto de la sociedad. Las enumeramos, aunque no nos detendremos en ellas, pero no dejarán de estar presentes en el fondo de nuestra reflexión: ¿las religiones tienen un papel público relevante que jugar en nuestras sociedades pluralistas y secularizadas?, ¿qué relación debe establecerse entre la Iglesia católica y las diferentes creencias y experiencias religiosas existentes en la sociedad española?, ¿cuál se establece de hecho?, ¿qué transformaciones se han producido en la relación entre factor religioso, mundo católico y sociedad española en el último cuarto de siglo?

Una de las primeras medidas tomadas por el nuevo Gobierno socialista ha sido la suspensión de la aplicación de la LOCE y, en concreto, de la nueva regulación prevista sobre la enseñanza de la Religión. Quizá ésta sea de facto una de las pocas consecuencias que tenga, a medio plazo, esta paralización: el bloqueo de área Sociedad, Cultura y Religión, prevista en la ley. Con este motivo, se han producido numerosas declaraciones sobre esta cuestión, y se ha avivado, de nuevo, el debate sobre la enseñanza de la religión en la escuela pública. No ha faltado, por otra parte, la confusión entre padres y profesores, en buena medida debida a afirmaciones y declaraciones, no siempre claras y bien informadas, de diversos responsables políticos, incluso del propio ministerio.

Hemos pensado conveniente reflexionar sobre esta cuestión ${ }^{3}$. ¿Qué pretende-

2 Ley orgánica 10/2002 de 23 de diciembre, de calidad de la educación. BOE nº 307, 24-12-2002, pp. $44.188-45.220$.

3 Para ello, el Consejo de Redacción de la Revista de Fomento Social invitó al prof. Carlos Esteban Garcés, director de la excelente publicación especializada Religión y Escuela, con quien compartimos una muy enriquecedora reflexión el 3 de junio de 2004, en ETEA. Ni que decir tiene que el consejo de redacción es el responsable único de todas las afirmaciones del editorial. mos con este editorial? Sin entrar en los numerosos detalles implicados en esta polémica cuestión, y dado el carácter de nuestra revista, nos ha parecido mejor proponer algunas reflexiones de fondo, sin las cuales todo el debate alrededor de este tema se quedaría corto y falto de una fundamentación. Además intentamos aportar elementos para lograr consensos en la materia. En una sociedad plural como la española, todos estamos llamados a dialogar abriéndonos a los razonamientos del otro e, inevitablemente, cediendo en parte, para poder conseguir algunos de nuestros objetivos profundos; estamos convencidos de que la dialéctica del "o todo o nada" no conduce a ningún buen resultado. No pretendemos, ni mucho menos, tener la última palabra; pero sí desearíamos poder contribuir de forma constructiva a la solución de un problema, al que nada favorecen ni la crispación ni los maximalismos de cualquier género.

Para tratar sobre la enseñanza de la religión en la escuela (ERE, a partir de ahora), después de una aproximación a su historia reciente (1), partimos de la perspectiva cultural en el actual contexto europeo, intentando responder a la pregunta: ¿qué pasa en nuestro entorno? (2); a continuación abordamos la cuestión antropológica de fondo: ¿por qué debe estar la religión en la escuela? (3); en cuarto lugar, nos detenemos en el enfoque jurídico-político de la cuestión: el derecho constitucional que las personas tienen a ser informadas sobre el hecho religioso y a ser formadas en la religión, puesto en relación con otros derechos fundamentales ${ }^{4}$ (4); al final intentamos ofrecer un conjunto de propuestas que sirvan para el debate social, para el logro de un deseable consenso político y legislativo sobre esta materia y, por último, para la gestión pública de este proceso (5).

\section{Aproximación histórica}

La Segunda República española establecía una «enseñanza laica (...inspirada) en ideales de solidaridad humana y reconocía "a las Iglesias el derecho, sujeto a inspección del Estado, de enseñar sus respectivas doctrinas en sus propios establecimientos" (Constitución de 1931, a. 48). Una enmienda presentada por el diputado Gil Robles defendía que "en el cuadro de las enseñanzas oficiales (hubiese) siempre un lugar para la enseñanza religiosa". El diputado católico

4 Aunque lo que decimos se puede extender a todas las escuelas, y muy concretamente a las concertadas y financiadas con fondos públicos, incluidas las que tienen la inspiración cristiana como su carácter propio, en nuestro editorial nos referimos fundamentalmente a las escuelas públicas. 
preveía el derecho de los padres a elegir la enseñanza religiosa que quisiesen para sus hijos y que ningún profesor oficial fuese obligado a enseñar una determinada religión. La enmienda fue rechazada. La República defendió una escuela laica: excluyente de cualquier presencia de la religión, entonces dominantemente la católica. La legislación de la Dictadura franquista, refrendada por el Concordato de 1953, restauró la confesionalidad del Estado y con ella la de la escuela: "En todos los centros docentes (...) la enseñanza se ajustará a los principios del dogma y de la moral de la Iglesia católica. Los ordinarios ejercerán libremente su misión de vigilancia sobre dichos centros docentes en lo que concierne a la pureza de la fe, las buenas costumbres y la educación religiosa. (...). El Estado español garantiza la enseñanza de la religión católica como materia ordinaria y obligatoria en todos los centros docentes. (...), (Concordato, 1953, a. 26 y a. 27.1). Durante cuatro decenios la enseñanza de la religión fue obligatoria para todos. Sólo excepcionalmente se arbitraron procedimientos de exención, sobre todo tras la Declaración sobre la Libertad Religiosa del Concilio Vaticano II (1965).

La Dictadura defendió hasta el final, incluso en la Ley General de Educación ${ }^{5}$, innovadora en tantos aspectos, una escuela confesional, la propia del nacionalcatolicismo que identificaba el ser español con la confesión católica, pretensión que se confiaba realizar desde el poder. En esa situación jurídica, pero con enormes cambios sociológicos, religiosos y culturales, llegamos a 1978. Ese año, al aprobarse la Constitución, se pusieron las bases actuales para considerar el problema.

\subsection{La transición democrática}

Si hemos evocado con brevedad esos precedentes del medio siglo anterior ha sido para recordar que existió una fuerte polaridad previa, falta de consenso y origen de mutuas y duraderas exclusiones. No es fácil entender lo que ha ocurrido después de 1978 si no se tiene en cuenta ese medio siglo anterior.

La solución constitucional se fue perfilando entre 1978 y 1980. Son los años en que se ponen las bases del actual ordenamiento jurídico español, y muy concretamente del llamado bloque de la constitucionalidad. Entendemos que,

5 "El Estado reconoce y garantiza los derechos de la Iglesia católica en materia de educación, conforme a lo concordado entre ambas potestades. Se garantiza asimismo la enseñanza religiosa y la acción espiritual y moral de la Iglesia Católica en los centros de enseñanza, tanto estatales como no estatales" (LGE, 1970, a. 6). además de la Constitución española (1978) que es su principio y fundamento, forman parte del mismo, tanto los Acuerdos suscritos entre del Estado español y la Santa Sede (enero de 1979, ratificados y publicados en diciembre de ese año), como la ley de libertad religiosa (1980). En cierta manera los decretos Otero Novas (1979-1980) y el decreto nunca aplicado, pero tampoco explícitamente derogado, de Mayor Zaragoza (octubre 1982) quisieron aplicar a la escuela aquellos principios constitucionales. En aquella etapa se intentó dar solución al principal y más urgente problema. En la sociedad pluralista que consagraba nuestra Constitución, había que integrar tanto el derecho de los padres a la educación religiosa de sus hijos de acuerdo con sus propias convicciones, como el derecho de quienes no quisiesen esa educación religiosa. El ministro Otero, con la colaboración de la Conferencia Episcopal y con muy escasa crítica, en aquellos momentos, ni en la opinión pública, ni en la izquierda, planteó como alternativa, para quienes no cursasen Religión católica, la enseñanza de la Ética. El ministro Mayor Zaragoza intentó, en octubre de 1982, dejar resuelto el estatuto del profesorado de religión en los centros públicos.

La Comisión Episcopal de Enseñanza de la Conferencia Episcopal, por su parte, hizo una interesante y profunda reflexión que ha marcado estos últimos veinticinco años, recogida en el documento de junio de 1979, La Enseñanza Religiosa Escolar. Orientaciones pastorales. Como resultado de la evolución de la concepción de la ERE entre 1939 y 1975, en ese momento coexistían tres posiciones. Legalmente apenas había habido cambios, pero en la práctica y en la reflexión interna de la Iglesia, especialmente a partir de los años del Concilio Vaticano II, se había pasado de un planteamiento más doctrinal (centrado en los conocimientos), a otro más catequético (centrado en la experiencia y en las actitudes), y finalmente a otro cultural (centrado en el diálogo en una sociedad cada vez más pluralista y en una aproximación crítica a la tradición). En el documento episcopal de 1979 se superaban las dos concepciones de enseñanza religiosa: la ERE como adoctrinamiento eclesial y la ERE como catequesis escolar de la experiencia; al mismo tiempo se cerraba el paso a una experimentación nacida a finales de los 60, la ERE como cultura religiosa, en la medida en que ésta pudiese conducir a una orientación aconfesional para la ERE.

El documento sobre la Enseñanza Religiosa Escolar proponía un concepto nuevo de ERE como "cultura religiosa confesional» que, con no pocas dificultades, ha ido abriéndose paso en la Iglesia española y ha sido bastante bien recibido por la propia sociedad. Para ese documento, la ERE es una materia plenamente escolar. La ERE, en cuanto cultura religiosa confesional es una exigencia de la escuela, que contribuye a tres finalidades educativas: situarse 
lúcidamente ante la tradición cultural, insertarse críticamente en la sociedad y dar respuesta al sentido último de la vida con todas sus implicaciones éticas. Nosotros también consideramos que estas tres finalidades educativas son un buen planteamiento de principio para una enseñanza religiosa a la altura de nuestras necesidades educativas y sociales en 2004.

Podemos decir que aquel período (1978-1982) se centró en la legitimación de la ERE en el sistema escolar, lográndose una reflexión interna nueva y buscándose una solución escolar por medio de la alternativa de Ética. Esta solución presenta algunos problemas importantes para ser aceptada como ideal, pero no podemos ignorar que también tuvo aciertos. Subrayamos dos: dejó claro que la ERE ya no podía ser impuesta, sino que debía ser motivo de elección; y permitió una adecuada estabilidad escolar, tanto para los alumnos de ERE como para la formación de quienes no cursaban ERE y elegían Ética, de forma que en los centros no había problemas prácticos importantes.

\subsection{Los gobiernos socialistas}

El fracaso del proyecto político de la UCD que, desde su posición política centrista y su ideología afín a la democratacristiana, había logrado un consenso sobre la ERE, y el triunfo electoral del PSOE, en octubre de 1982, llevaron a la sociedad española a otro escenario. En la práctica la ERE sufrió a partir de entonces un progresivo deterioro en su presencia y estabilidad en la escuela. La fórmula alternativa entre Religión católica y Ética siguió vigente hasta la aprobación de la LOGSE (1990) y, en la práctica, hasta mediados de los 90 cuando se fue generalizando la implantación de la ley, pero desde 1983 quedó claro que el nuevo equipo ministerial no estaba de acuerdo con una presencia estable de la ERE en la escuela y que ésta iba a sufrir un progresivo hostigamiento. En el largo período de gobierno del PSOE, podemos distinguir, aún así, tres períodos, vinculados a tres ministerios: la práctica de la suplantación legislativa (Maravall, desde 1982), la reducción constitucional (Solana Madariaga, con la LOGSE, 1990) y el intento final de consenso (Suárez Pertierra, en la última legislatura).

Desde el principio el PSOE hizo otra lectura del derecho constitucional de los alumnos (y de sus padres) a una enseñanza de acuerdo con las propias convicciones (Const., a. 27.3) y del pleno desarrollo de la personalidad humana (Const., a. 27.2), los dos ejes constitucionales en los que se fundamenta la ERE. El Gobierno disoció ambos principios, asumió como competencia propia la dimensión de integralidad (a. 27.2) y se limitó a respetar escrupulosamente la protección del derecho a la educación según las propias convicciones (a. 27.3), como algo que era particular de algunos ciudadanos, pero no generalizable.

Desde el Ministerio se impulsaron políticas de continuo deterioro de la ERE y se apostó por un cumplimiento formal de lo legislado, pero con la antigua tradición decimonónica hispana de la práctica de la suplantación con circulares y órdenes de los niveles intermedios, cuidando escrupulosamente no vulnerar la letra del Acuerdo con la Santa Sede de 1979 sobre enseñanza y asuntos culturales, ni, por supuesto, la propia Constitución. Fue entonces evidente que lo único que se consideraba era el derecho que algunos ciudadanos tenían a ser educados de acuerdo con sus propias convicciones; para la administración educativa, este derecho era una expresión individual que no quedaba más remedio que admitir, pero que no había que apoyar, sino reducir al máximo. Esta política deliberada llevó como resultado a que, en la gran ley educativa de la etapa socialista, la LOGSE (1990), la ERE quedase reducida a una mención en la disposición adicional segunda ${ }^{6}$, fuera del currículo escolar, que justificaba su presencia tan sólo en el cumplimiento de un derecho subjetivo, amparado en unos Acuerdos internacionales. Era el final de una lógica de exclusión de la ERE del cuadro de finalidades de la escuela y de reducción de la misma a una actividad complementaria.

Los seis años que siguieron a la LOGSE abrieron el camino a una progresiva inestabilidad de la ERE en el sistema escolar. La reacción de algunos grupos de ciudadanos permitió que, tras sucesivas sentencias judiciales, se fuesen rechazando las propuestas organizativas del gobierno, que intentaba contraponer a la ERE unas actividades devaluadas, que obligaban a los alumnos a hacer elecciones asimétricas. Frente a una asignatura, los alumnos recibían la oferta de un tiempo adicional de 'estudio asistido', actividades lúdicas varias o complementarias (el famoso 'parchís') o, en muchos casos, la exención de cualquier actividad (el 'patio'). A pesar de los esfuerzos de algunos inspectores, directores y claustros por dignificar académica y educativamente esa opción, la alternativa muchas veces quedaba reducida a 'religión o nada'. De este largo

6 "La enseñanza de la religión se ajustará a lo establecido en el Acuerdo sobre enseñanza y asuntos culturales suscrito entre la Santa Sede y el Estado Español y, en su caso, a lo dispuesto en aquellos otros que pudieran suscribirse con otras confesiones religiosas. A tal puesto en aquellos otros que pudieran suscribirse con otras confesiones religiosas. A tal
fin, y de conformidad con lo que dispongan dichos acuerdos, se incluirá la religión como área o materia en los niveles educativos que corresponda, que será de oferta obligatoria área o materia en los niveles educativos que corresponda, que será de oferta obligatoria
para los centros y de carácter voluntario para los alumnos", LOGSE, disposición adicional para los centr
segunda. 
período nos ha quedado el progresivo deterioro a que fue sometida la ERE, que fue especialmente llamativo en la educación secundaria (12-18 años) y en los centros públicos. En algunos institutos de periferias urbanas y en algunas regiones más secularizadas, la ERE dejó de existir como opción escolar, y en otros muchos centros quedó reducida a porcentajes mínimos. Es cierto que en el conjunto no hubo una tan llamativa reducción pues en la enseñanza primaria (6-12 años) se mantuvo un alto índice de aceptación, así como en ciertos tipos de centro y en algunas regiones.

Esta etapa de práctica de suplantación y, después, de reducción constitucional, tuvo un final breve, pero todavía interesante. Con el ministro Suárez Pertierra, jurista de formación, canonista para ser más precisos, se ensayó una fórmula que era prometedora y que, desde entonces, no ha dejado de ofrecer algunas perspectivas. Tras los sucesivos rechazos judiciales a las fórmulas de deterioro que desde la administración se propiciaban, el último gobierno de Felipe González intentó una solución más incontestable y duradera. El ministro Suârez Pertierra convocó una comisión de notables para que pensase fórmulas respetuosas con la legalidad vigente y con la pluralidad social. De aquella comisión surgió el proyecto de una alternativa a la ERE, pensada inicialmente para los tres años equivalentes al anterior BUP, es decir para $3^{\circ}$ y $4^{\circ}$ de ESO y $1^{\circ}$ de Bachillerato. Esa alternativa tenía un programa, era evaluable y había de ser impartida por profesores competentes. La asignatura recibió el nombre de Sociedad Cultura Religión.

De este largo período (1982-1996) retenemos algunos hechos más significativos: el progresivo deterioro de la situación de la ERE, la escasa reacción social ante el mismo, la reflexión sobre la necesidad de su evaluación, si se quería que tuviese sentido dentro del sistema escolar y, por último aunque no menos importante, cierta involución eclesial en la consideración de la ERE.

\subsection{Los gobiernos de centroderecha}

El período del gobierno del PP que comenzó en 1996 encontró esta situación y pronto comenzaron algunos cambios orientados a una modificación de la situación de la ERE en el conjunto del sistema educativo, que mejoraba, sobre todo, dos aspectos: la situación laboral y salarial de los profesores, especialmente del amplísimo colectivo de docentes de religión en enseñanza primaria y primer ciclo de secundaria ( $1^{\circ}$ y $2^{\circ}$ de ESO). El otro cambio importante, que mejoró la situación de la ERE consistió en ofrecer a los alumnos una elección más equilibrada en cuanto al contenido alternativo a la opción de religión católica. En estos años, por otra parte, las diferentes confesiones religiosas habían continuado suscribiendo acuerdos con el Estado y la opción confesional ya no era exclusivamente la católica. Los diferentes acuerdos de las Comunidades Autónomas gobernadas por el PP (muy significativamente Galicia al principio; más tarde, Madrid) o por los nacionalistas vascos y catalanes, con las Iglesias locales habían introducido una práctica pluralista y correctora de la legislación socialista y habían preparado el terreno para una reforma global. En la primera legislatura del PP hubo algunos intentos de hacer esta reforma, entre otros un significativo y bastante cuestionado proyecto del ministro Rajoy ${ }^{7}$, que no llegó a serdiscutido en el Congreso. Desde el punto de vista legal hubo una modificación del estatuto del profesorado que dignificaba la función y estabilidad docente, sin que desapareciese uno de los mayores problemas existentes: el ilimitado poder de contratación, destino y cese del que goza la autoridad eclesiástica, que deja a la administración civil como mera ejecutora de decisiones que se toman fuera de la misma. En realidad, sin embargo existe una gran estabilidad en el profesorado de ERE, por lo que no es tanto la práctica como el principio lo que es en sí mismo objetable.

El final del gobierno del PP vio cómo, tras la aprobación de la LOCE, la ERE accedía al estatuto de plena curricularidad, con dos modalidades, una confesional (con plurales opciones) y otra aconfesional, dentro de una misma área curricular, que recibía el nombre de Sociedad Cultura y Religión. La Ley orgánica de calidad de la educación (LOCE, de la ministra Del Castillo, diciembre de 2003) dio a la ERE una regulación inicialmente coherente con el texto constitucional y el bloque de la constitucionalidad. La propuesta de la LOCE era una solución acertada y progresista (pero no laicista), aunque políticamente inestable, como hemos tenido ocasión de comprobar en las últimas semanas. Como hemos dicho al principio ésta no era una buena solución por una simple razón: se hizo sin consenso social ni parlamentario. La LOCE reguló, por primera vez de forma explícita en una Ley Orgánica ${ }^{8}$, la enseñanza

7 Ese intento de decreto nonnato, el borrador Rajoy, apareció en la prensa a primeros de noviembre de 1999 .

8 La LOGSE (1990) se ocupó de la ERE sólo en su sentido confesional y sólo para hacer una regulación que se limitaba a remitir a los Acuerdos concordatarios de enero de 1979, y no entraba en el fondo de la cuestión, ignorando, sin negarlas, las perspectivas abiertas por la Constitución, la Ley Orgánica del Derecho a la Educación y la Ley Orgánica de Libertad religiosa. 
de la religión en su modalidad confesional y en la no confesional ${ }^{9}$. En la LOCE se establece que el área o asignatura (según las diferentes etapas educativas) Sociedad Cultura y Religión es, según la LOCE, actualmente suspendida en su aplicación, obligatoria para todos los alumnos ${ }^{10}$, con dos opciones de desarrollo: confesional y no confesional.

\subsection{Evolución eclesial}

Aunque el documento de 1979 nunca ha sido sustituido, ni formalmente contestado, en la práctica, junto al esfuerzo muy notable de muchas diócesis en la selección del profesorado, en su formación inicial y continua, y en el apoyo editorial, didáctico, etc., a la ERE como cultura religiosa confesional, en amplios terrenos ha ido abriéndose paso una tendencia más fuerte de control eclesiástico y un cierto retorno a posiciones más doctrinales y menos culturales en la fundamentación de la ERE. Con frecuencia se afirma la ERE como una acción pastoral de la Iglesia, complementaria de otras acciones evangelizadoras, en la que importa mucho la vinculación visible eclesial del profesor, del que

9 En su disposición adicional segunda la LOCE establecía: "Del área o asignatura de Sociedad Cultura y Religión. 1. El área o asignatura de Sociedad, Cultura y Religión comprenderá dos opciones de desarrollo: una de carácter confesional, acorde con la confesión por la que opciones de desarion por la que opten los padranza el Estado tenga suscritos Acuerdos, otra, de carácter no confesional. Ambas opciones serán ne oferta obligatoria para los centros, debiendo elegr los alumnos una de ellas. 2. La ensenanza contesional de la Relgón se ajustará a lo establecido en el Acuerdo sobre enseñanza y asuntos culturales suscrito entre la Santa Sede y el Estado Español y, en su caso, a lo dispuesto en aquellos otros suscritos, o que pudieran suscribirse, con otras confesiones religiosas. 3. El Gobierno fijará las enseñanzas comunes correspondientes a la opción no confesional. La determinación del currículo de la opción confesional será competencia de las correspondientes autoridades religiosas. Las decisiones sobre utilización de libros de texto (...)”. Para desarrollar la LOCE, el Gobierno aprobó tres RR. DD. de 27 de junio, 830/2003 831/2003 y 832/2003 por los que se establecían respectivamente las enseñanzas comunes de la Educación Primaria, de la Educación Secundaria Obligatoria y del Bachillerato. Con ellos se da un paso más, ciertamente importante, para la implantación del nuevo modelo de enseñanza religiosa escolar.

10 En realidad esta proposición es tan antigua como la propuesta que, en febrero de 1989, aprobó la Comisión Episcopal de Enseñanza que, con importantes modificaciones posteriores introducidas por presión de los sectores eclesiásticos más conservadores, fue presentada al Ministerio de Educación en abril de ese mismo año (cf. J. M. MARGENAT (1989) "Religión para todos" en La Vanguardia, Barcelona, 5-2-1989). Era entonces presidente de la Comisión Episcopal de Enseñanza el arzobispo de Valladolid; de éste, puede verse J. Delicado BAEZA (1989) “La enseñanza de la Religión”, Razón y Fe 220, 175-180. se subraya su condición de testigo y la necesidad de que exprese la comunión eclesial. Con la misma partitura del documento de 1979, que subraya más el derecho de los ciudadanos a una formación integral y el carácter fuertemente cultural de la ERE, desde principios de los 90 hemos escuchado otras músicas: ciertas tendencias a la reconfesionalización eclesiástica de la ERE, en merma de su carácter cultural, abierto a todos los alumnos, aún los no creyentes; reconfiguración catequético-doctrinal en detrimento del carácter escolar y curricular; subrayado de la condición confesante del profesor, por encima de su consideración profesional como un docente cualificado responsable de una materia escolar Es posible que ésta sea una reacción lógica defensiva ante el hostigamiento continuado que ha sufrido la ERE en esos mismos años.

En resumen, podríamos decir que del período de la UCD (1977-1982) nos queda el equilibrio escolar y la superación de la discriminación; del período del PSOE (1982-1996), la reflexión sobre la evaluación y la primera propuesta sobre un área cultural de enseñanza religiosa; y del período del PP (1996-2004) nos queda un intento bien fundamentado para alcanzar un planteamiento educativo para la ERE.

\section{El contexto europeo}

En estos veinticinco años en Europa se han producido cambios sociales importantes. En España han sido aún más acelerados. No podemos, siquiera, apuntar algunos rasgos sociológicos que influyen en la relación entre el factor religioso y la escuela y que, por ello, se convierten en retos sociales a la escuela en materia religiosa. Excede nuestras posibilidades actuales y el espacio posible para este editorial. Después de una sumaria enumeración de algunos síntomas que están modificando esta relación entre factor religioso y sociedad, nos detendremos en exponer las tres formas con que en Europa se ha resuelto la relación del factor religioso en la escuela. Esta tipología básica nos permitirá pasar, en el apartado conclusivo, a nuestras propuestas para el diálogo.

\subsection{Europa, una sociedad en cambio}

La sociedad europea actual, en el tiempo de la mundialización acelerada, ha vuelto a plantear la cuestión de la vinculación social y de la ciudadanía común. Los sistemas de cohesión social basados en el Estado de Bienestar redistribuidor de renta e integrador de clases sociales antagónicas y de un Estado laico y neutral que garantiza el respeto de las comunidades religiosas, ha 
dejado de responder a las necesidades sociales más urgentes y más profundas. El triunfo del relativismo cultural cuestiona el mismo fundamento del Estado laico, la llamada laicidad republicana en Francia, y cuestiona el papel de la escuela como medio único de integración. En estos años en toda Europa se reabre el debate de la necesidad de una educación más integral como principio equilibrador de la disgregación social. Tanto la marginación social (y económica, que está en su base, la llamada sociedad dual), como la masiva inmigración plantean otras exigencias al consenso social. El pacto social y el pacto escolar no son un resultado estable que garantiza un equilibrio entre lo público y lo privado, entre la integración y la pluralidad. Las sociedades nacionales ya no tienen ni la garantía ni los instrumentos para construir ese consenso. Mundialización comercial y financiera, globalización mediática, multiculturalismo social y desagregación social hacen, de día en día, menos evidente nuestro modelo social.

Por otro lado, después de la segunda Guerra Mundial y, de forma mucho más acelerada, tras la fractura cultural de finales de los años 60 y la crisis económica que puso fin a los treinta gloriosos años de crecimiento ininterrumpido, Europa vive en un permanente estado de crisis de la transmisión comunitaria de las tradiciones de sentido. Por un lado se ha producido, como hecho nuevo en esos años, especialmente tras el Concilio Vaticano II, la secularización interna de una Iglesia atravesada por la modernidad, y por otro, algo mucho más llamativo, la exculturación del cristianismo de la sociedad europea. Europa sigue siendo culturalmente cristiana, postcristiana para decirlo con más precisión, pero las Iglesias, tanto la católica como las protestantes, las ortodoxas y la anglicana, son minorías cognitivas, en sus respectivas sociedades, productoras de unos referentes simbólicos y de unos contenidos culturales que han dejado de ser comprensibles para muchos segmentos de las sociedad europea. Es claro que esta situación no afecta por igual a todos los países, incluso a las diferentes regiones, ni tampoco a todas las iglesias, pero podríamos convenir en que ésta es una característica general de las sociedades europeas, atravesadas por el síndrome de lo post: sociedad postindustriales, postcristianas, postradicionales, postmodernas. Las tradiciones de sentido pasan por un mal momento en Europa pues se debaten entre la reclusión comunitarista, con riesgo de devenir movimientos sectarios incapaces de presencia pública y propensos a fundamentalismos o integrismos de cualquier tipo, y la salida constante a la intemperie, con la erosión permanente de sus sistema de cohesión simbólica y la necesidad de entrar en un sistema desregulado de acceso a las creencias, a las experiencias y a los símbolos religiosos.
En estos años hemos conocido el fin del monopolio eclesial de la transcendencia. Las diferentes comunidades no controlan ya sus propios sistemas, sino que se ven obligadas a ofrecer estos en un mercado abierto, donde florece lo que algunos han llamado nuevas formas de religiosidad peregrina y de religiosidad salvaje. Los alumnos que acceden a la escuela, y potencialmente a una ERE, son miembros de una sociedad, e hijos de ciudadanos que viven inmersos ya en lo que conocemos como la desregulación institucional de las creencias, los símbolos y los sentimientos religiosos. Los valores propios de los alumnos, de las familias, de sus comunidades, se cierran en guetos o sufren una fuerte migración interior. Nunca como ahora, las iglesias habían significado tan poco para la conformación de las identidades personales y sociales (de grupo, nacionales, y europea).

El reciente debate sobre la referencia a las raíces cristianas de Europa ha dejado ver a las claras, la fragilidad de la propuesta y la intranscendencia de la misma para amplias capas de opinión. No eran los menos los que estaban dispuestos a apoyarla, pero no se comprometían a batallar por esta causa. En el fondo a la mayoría de los europeos, y de los españoles, es un asunto que les parece muy secundario. Junto a este vaciamiento de intensidad de la religión institucional, de las confesiones o iglesias establecidas, Europa ha conocido la sacralización de formas culturales seculares, entre ellas, en primer lugar, la familia, que goza de una excelente salud en la valoración de los ciudadanos, aunque sea en su forma desregulada y electiva actualmente vigente, y la naturaleza. En esta religiosidad polimorfa de los europeos de comienzos del siglo $X X I$, la satisfacción de las necesidades inmediatas parece ser el criterio que acompaña a la búsqueda de las pequeñas e intermedias transcendencias. En ese mundo coexisten todas estas formas a que hemos aludido, con ese mundo llegan los alumnos a la escuela. Este cambio mayor influye lógicamente en la manera con que la escuela puede afrontarse al hecho religioso.

El diálogo cultural, la construcción de sistemas de cohesión social a partir de la interculturalidad y, por último, la necesidad inaplazable de establecer un verdadero diálogo interreligioso en Europa, nos conducen a un cuarto aspecto que habría que tratar para dar cuenta de la problemática que rodea a la ERE. En la Europa poscristiana y religiosamente plural, los ciudadanos, los creyentes de las diferentes religiones -y de forma especial sentimos que esto nos afecta a los católicos- hemos de aprender a ser y a vivir juntos de nuevo. Estos dos pilares de la educación nos lanzan por el camino de descubrir nuevas formas de presencia escolar y cultural, nuevas espacios de diálogo, nuevos medios de transmisión de las creencias y valores. Como ya hemos indicado anterior- 
mente el diálogo intercultural sólo podrá hacerse si estamos preparados para el diálogo interreligioso.

La ERE habrá de preparar especialmente para afirmaciones dialogantes y críticas de las propias convicciones y creencias y para permitir la convivencia en la pluralidad. Reconozcamos que ésta es una tarea apasionante y un reto difícil para el que no nos sentimos preparados ni como iglesias, ni como ciudadanos. No podemos dejar que pase más tiempo sin fomentar esa formación que nos va a permitir vivir juntos y ser quienes somos en un mundo cada vez más plural, un mundo que se rige por consensos frágiles que hay que fundamentar, renegociar y sostener continuamente, sociedades en debate permanente. No nos da miedo ni como ciudadanos ni como cristianos. Partimos de un patrimonio, el Evangelio encarnado en nuestra cultura, un modelo social garante de equilibrios profundos, abierto a las solidaridades interterritoriales, y de una cultura política y jurídica que se afirma sobre la dignidad humana y los derechos fundamentales de las personas. Pero no podemos dejar pasar más el tiempo en disputas estériles, hemos de hacernos capaces para ese diálogo fundante de nuestro vivir juntos.

2.2. Tres modelos europeos de regulación de la enseñanza religiosa escolar

La historia moderna de Europa ha ido configurando un marco jurídico-cultural con el que se corresponden tres modelos escolares de inserción de la ERE en el currículo. Estos tres modelos existentes en los Estados de la Unión Europea son la laicidad escolar, excluyente de la ERE, la cooperación escolar de las Iglesias para la ERE y la plena integración escolar de dicha enseñanza. Si queremos visualizar los modelos nos podemos referir a Francia, a Italia y a Alemania. Si los denominamos en relación con el currículo la clasificación sería ésta: extracurricularidad simple (Francia), curricularidad subjetiva (Italia) y curricularidad objetiva (Alemania).

Al presentar estos tres modelos, lo hacemos en su complejidad histórico-jurídica-cultural, que está relacionada con la forma como se ha organizado la institución escolar. Estos modelos son diferentes y responden a sucesivas evoluciones internas a cada sociedad. Por ello cambian con mucha dificultad. Los ámbitos de regulación de la vida común -los espacios simbólicos, la construcción jurídicas, los resultados decantados en el cuerpo político-son fruto de conflictos a veces muy hondos, de pactos difíciles, pero por eso muy resistentes. Estas configuraciones responden a las culturas de los países y cambian mucho más lentamente que las dinámicas reguladas por el mercado, o incluso que el mundo de los intercambios regulados por los medios de comunicación social. Es más, con frecuencia se añade una factor de especial resistencia al cambio por cuanto forman, frente a otras realidades más difuminadas y compartidas un espacio de identidad de cada nación, sociedad, etc. En nuestra descripción intentamos presentar el modelo en su lógica interna, intentando comprender su racionalidad; aunque esbozamos algunas de las dificultades actuales, evitamos hacer una valoración general de los mismos.

Los modelos se describen, además, como tipos ideales, pero hay que anotar que están cambiando continuamente y que se atraen entre sí. Por otro lado, los países que incluimos en cada modelo tienen, entre ellos, variantes muy importantes. En última instancia, también la homologación mediático-cultural y la unificación mercantil hace que se vayan difuminando algunas diferencias y características identitarias. La generalizada laicización de la vida pública, la duradera privatización de lo religioso y la desregulación de las creencias son hechos comúnmente reconocidos en todos los países europeos. Esta constatación no significa negar lo específico que tiene cada modelo, pero tampoco éstos pueden ser tomados como referentes aislados o absolutos e inamovibles.

\section{a) Laicidad escolar}

Aunque este modelo en estado puro sólo se dé en Francia (aún con la excepción de los departamentos concordatarios de Alsacia y Mosela) y en algún pequeño país del Este (como Eslovenia), el modelo ideal, como tal, ejerce un atractivo muy fuerte en todo el continente (por ejemplo en los Países Bajos o en Portugal) y por ello retiene una importancia notable. El modelo se configura a partir de la fundación de la República laica, que es mucho más que una mera forma de gobierno, es una cultura y un pacto social. Esta fundación político-legislativo-cultural se produce a lo largo de los 116 años que median entre la revolución de 1789 y las leyes de separación de Iglesia y Estado de 1905. La laicidad escolar parte de la necesaria exclusión escolar de cualquier tradición particular, por mayoritaria que sea, como fundamento de la educación republicana. Ésta se refiere a los valores mínimos aceptados por toda la sociedad y por todas las personas en cuanto miembros de la comunidad política. Estos valores se expresan en los derechos humanos y en la cultura del pacto republicano, que considera todo lo religioso como un factor perteneciente al ámbito privado personal o de las comunidades. Las religiones son tradiciones particulares, y son generadoras de vinculaciones particulares, incompatibles 
con la escuela laica. Ésta se funda en la educación de la ciudadanía, y para ello se basa en el pacto republicano y excluye de manera no arbitraria a las religiones.

La educación laica, para fundar una moral de todos, se construye sólo con lo que es común. Lo que diferencia, lo que se presenta como diferenciador y signo de una identidad no compartida («signos ostensibles», dice la reciente ley del velo), debe quedarse a las puertas de la escuela. En los últimos años se ha producido un fuerte debate en Francia a propósito de esta cuestión: primero en la segunda mitad de los ochenta sobre el velo, que se ha repetido muy recientemente; luego, a mediados de los 90, a propósito del patrimonio cultural religioso de los estudiantes franceses (o más bien de su escasísima cultura religiosa). Hoy, tanto en Francia como en otros países, se discute si es posible mantener este modelo, o si no habrá que plantearse un cierto reconocimiento de lo religioso como integrante esencial de lo humano. ¿Cabe educar dejando al margen un factor esencial? Por otro lado, la novedad viene presentada por la irrupción de religiones nuevas que no han asimilado la laicidad republicana, como ya lo tenían realizado el catolicismo, el protestantismo y el judaísmo. No cabe duda, pues, que para muchos ciudadanos, entre los que hay un importante número de católicos, la religión no forma parte del vínculo social común y no debe pretender estar en la escuela. Otros sectores, musulmanes por ejemplo, pero también amplios grupos católicos, etc. plantean la necesidad de revisar el estatuto escolar de las religiones; por último, muchos, también, en todas posiciones, se preguntan por la necesidad de una enseñanza cultural de la religión, que hasta fechas recientes garantizaban las iglesias, pero a la que ahora no accede la mayoría de alumnos. Estos sectores y líderes de opinión piensan que la ignorancia sobre lo religioso puede llegar a impedir a los espíritus contemporáneos, especialmente a quienes no pertenecen a comunidades religiosas, el acceso a las obras mayores del patrimonio artístico, literario y filosófico. La laicidad escolar configura un sistema en el que la religión queda fuera del horario común. Como es sabido en Francia hay una tarde prevista para la enseñanza religiosa, confiada a encargados nombrados por las confesiones, que se realiza en el espacio escolar (locales de la aumônerie) y que financian las iglesias. La religión no es ignorada, pero queda excluida del currículo. La religión no es enseñada, simplemente porque no forma parte del currículo común, el de todos los alumnos. Es el modelo que llamamos extracurricularidad simple.

\section{b) Cooperación escolar}

En los países de tradición católica, aunque no en todos, que suelen haber configurado una tradición concordataria, pero también en otros (España, Italia, los departamentos Alsacia y Mosela en Francia, que entre 1870 y 1918 pertenecieron al Reich y tuvieron Concordato, Malta, Irlanda, Polonia, etc.) se ha ido configurando un estatuto bastante diferente al anterior. Como resultado de los procesos de secularización estatal del $s$. XIX y primera mitad del $s$. XX los Estados llegaron a acuerdos (concordatarios o de otro rango) con la Santa Sede reconociendo un estatuto para la Iglesia católica como factor público que ha configurado la historia nacional. Las formas varían, pero la lógica subyacente es similar: la religión forma parte de lo público, del patrimonio social o cultural nacional. Normalmente las constituciones de estos Estados definen a éstos como aconfesionales, sin una religión propia de la nación, pero reconocen algún papel positivo a la existencia del hecho religioso, y se obligan, a partir de ese reconocimiento, a mantener algunas relaciones de cooperación institucional. Es muy frecuente que este reconocimiento se consagre en acuerdos con las confesiones religiosas, en concreto en concordatos con la Iglesia católica.

La enseñanza religiosa, en estos países, se justifica sobre todo, aunque no exclusivamente, como medio para formar a los alumnos en cuanto miembros de una confesión y, por eso mismo, intervienen las Iglesias, a las que se les pide una cooperación que el Estado no confesional necesita de ellas. Por esta misma lógica se entiende que el Acuerdo de España con el Vaticano, firmado en $1979^{11}$, diga que la enseñanza de la religión es una asignatura, "en condiciones equiparables a las demás disciplinas fundamentales», que responde al «derecho fundamental» que el Estado reconoce a la educación religiosa, garantizado en su ejercicio por pactos internacionales, y, lo que no deja de tener interés, se reconoce que "el patrimonio histórico, artístico y documental de la Iglesia sigue siendo parte importantísima del acervo cultural de la nación». En el Acuerdo de 1985, ratificado en 1986, firmado por el Gobierno italiano que presidía Bettino Craxi, que revisaba y actualizaba el Concordato, parte de los Pactos lateranenses de 1929, se afirmaba: «La República italiana, reconociendo el valor de la cultura religiosa y considerando que los principios del catolicismo forman parte del patrimonio histórico del pueblo italiano, continuará asegurando, en el cuadro de las finalidades de la escuela, la enseñanza de la religión católica en las escuelas públicas no universitarias de todo tipo y grado". Este modelo de

${ }^{11}$ Acuerdo sobre enseñanza y asuntos culturales suscrito entre el Gobierno español y la Santa Sede de 3 de enero de 1979, ratificado por instrumento de 4-XII-1979 (BOE, 15-12-1979). 
integración desde la cooperación con las confesiones da lugar a un estatuto de curricularidad subjetiva. La religión es enseñada porque forma parte esencial del currículo de todos aquellos alumnos que por pertenecer a una confesión (o, de forma secundaria, por interés personal) quieren acceder a esta enseñanza, pero no forma parte del currículo común, sino del fundamental de una parte de la población escolar. Es el modelo que, por esta razón, hemos llamado curricularidad subjetiva.

\section{c) Integración escolar}

En Europa occidental y central, así como en Escandinavia, hay un área cultural que viene a coincidir con los países que vivieron las reformas religiosas del s. XVI y XVII (luteranismo, anglicanismo, calvinismo), donde hay o bien religiones de Estado, o bien iglesias establecidas en Estados pluriconfesionales. Todos los países escandinavos e Inglaterra y Gales pertenecen al primer grupo, mientras que en el segundo encontramos a Alemania, Suiza, Bélgica, Croacia, Austria, Luxemburgo (éste con garantía concordataria) e Irlanda; en otra área cultural está Grecia que es un Estado confesionalmente cristiano ortodoxo, con una enseñanza confesional. Por otro lado, en Inglaterra la enseñanza de la religión es interconfesional. En todos estos países la enseñanza de la religión forma parte del currículo básico, en la mayoría de los casos es confesional y en otros no lo es, y cuando hay (lo que no sucede siempre) una materia alternativa como Ética o Historia de las religiones, ésta es también obligatoria. En estos países se entiende que la enseñanza de la religión forma parte, a todos los efectos, del patrimonio cultural común y, por tanto, está totalmente integrada en el horario. La enseñanza religiosa llega incluso a estar reconocida expresamente en el ordenamiento constitucional, como en el caso de Alemania. La Ley fundamental (Grundgesetz) de Bonn de 1949 establece en su artículo 7.3 que «la enseñanza religiosa constituirá una asignatura ordinaria en las escuelas públicas». Tanto la dotación de profesorado como los medios materiales de que dispone es similar a las demás asignaturas. Por ello podemos hablar de un modelo de plena integración escolar que da lugar a un estatuto de curricularidad objetiva. La religión es enseñada porque forma parte del currículo de todos, del currículo común.
Cuadro de los modelos de enseñanza de la religión escolar en Europa

\begin{tabular}{|c|c|c|c|c|}
\hline \begin{tabular}{|l|} 
Modelos \\
escolares \\
\end{tabular} & $\begin{array}{l}\text { Formas de } \\
\text { integración de la ERE }\end{array}$ & Países & Legislación reguladora & $\begin{array}{l}\text { Estatuto de las } \\
\text { Iglesias }\end{array}$ \\
\hline $\begin{array}{l}\text { Laicidad } \\
\text { escolar }\end{array}$ & $\begin{array}{l}\text { Extracurricularidad } \\
\text { simple }\end{array}$ & Francia & \begin{tabular}{|l} 
Leyes: \\
- Exclusión de la \\
enseñanza religiosa, \\
1881 y 1886 \\
- Separación, 1905 \\
- Constitución de \\
1958 \\
\end{tabular} & $\begin{array}{l}\text { Iglesias excluidas } \\
\text { de la vida pública y } \\
\text { separación total entre } \\
\text { Estado e Iglesias }\end{array}$ \\
\hline $\begin{array}{l}\text { Cooperación } \\
\text { escolar }\end{array}$ & $\begin{array}{l}\text { Curricularidad } \\
\text { subjetiva }\end{array}$ & Italia & $\begin{array}{l}\text { - Concordato } \\
\text { Mussolini, } 1929 \\
\text { - Revisión del } \\
\text { Concordato, Craxi, } \\
1986 \\
\end{array}$ & $\begin{array}{l}\text { Iglesias reconocidas } \\
\text { como factor público } \\
\text { y/o concordatarias }\end{array}$ \\
\hline $\begin{array}{l}\text { Integración } \\
\text { escolar }\end{array}$ & $\begin{array}{l}\text { Curricularidad } \\
\text { objetiva }\end{array}$ & Alemania & $\begin{array}{l}\text { - Grundgesetz, Bonn, } \\
1949\end{array}$ & $\begin{array}{l}\text { Iglesias establecidas } \\
\text { e Iglesias nacionales }\end{array}$ \\
\hline
\end{tabular}

Fuentes diversas. Elaboración propia.

\section{La cuestión de fondo: ¿por qué la religión en la escuela?}

Antes de presentar nuestras propuestas creemos conveniente explicar las razones desde las que las hacemos. Aunque se haya hecho muchas veces, no deja de ser necesario que nosotros respondamos a la pregunta del porqué de la religión en la escuela.

\subsection{La educación permite situarse ante la realidad total}

La finalidad de la educación escolar, según el artículo 27.2 de la Constitución española, al igual que el artículo 26 de la Declaración Universal de los Derechos Humanos, es el pleno desarrollo de la personalidad. En este precepto los constituyentes se refirieron a la función que tiene que tener la actividad educativa que se desarrolla en los centros docentes. El pleno desarrollo de la personalidad constituye el objetivo último del sistema educativo. El importante acervo de conocimientos, las destrezas y habilidades y, por último, actitudes, como la autonomía del sujeto, el espíritu crítico, el sentido de la responsabilidad, etc., y los valores conforman el conjunto de los contenidos educativos que contribuyen a este desarrollo pleno de la personalidad de los alumnos.

El propio artículo 27.3 de la Constitución, al establecer que los poderes públicos garantizan el derecho que asiste a los padres para que sus hijos reciban la 
formación religiosa y moral que esté de acuerdo con sus propias convicciones, da por supuesto que la educación no se puede circunscribir, exclusivamente, a un conjunto sistemático de conocimientos, sino que presupone también una formación religiosa y moral. Por su parte, el Tribunal Constitucional ha definido la enseñanza como "la actividad encaminada de modo sistemático y con un mínimo de continuidad a la transmisión de un determinado cuerpo de conocimientos y valores". Con otras palabras, la escuela debe ayudar a conocer y comprender el "mundo" y también, qué duda cabe, debe preparar para criticarlo, valorarlo y tomar decisiones en él y ante él. En la escuela deben estar presentes aquellos saberes que contribuyen decisivamente a cumplir con esta finalidad; por ello el sistema educativo no debe limitarse a formar personas pensando exclusivamente en su incorporación futura al mercado de trabajo o a la sociedad de consumo. Los objetivos educativos, vistos en perspectiva, son mucho más ambiciosos.

Para llegar a entender mínimamente la realidad en la que se inserta el hombre, es preciso que comprenda básicamente todas sus dimensiones. Entre ellas está el mundo de la naturaleza, del que se ocupan esencialmente las ciencias experimentales, y todo aquello que es pura creación del hombre: el mundo de la cultura, en el que nace y se desarrolla cada persona. El ser humano, y cada hombre en particular, no se puede entender si se prescinde de este universo cultural. Probablemente éste es que más moldea y cambia a cada hombre en particular, el que más le limita, pero también, paradójicamente, el que más le potencia (es lo que algunos sociólogos denominan la dualidad de las estructuras culturales): es el que más influye en el desarrollo biográfico de cada persona. Pues bien, no es aventurado afirmar que una cultura no se puede entender si se prescinde del hecho religioso, de su análisis, de su estudio y de su valoración. El hecho religioso y las diferentes religiones siguen siendo algo presente en la realidad del hombre y, probablemente, siempre le acompañarán. Muchos antropólogos y sociólogos consideran al hombre como un ser religioso, si bien no siempre individualmente hablando, sí desde el punto de vista cultural: y es que donde hay una cultura parece haber siempre una religión. Renunciar, pues, a la educación escolar del hecho religioso es prescindir de un dato de la realidad sin el que no podemos llegar a conocer el mundo. Renunciar a esa dimensión no sería simplemente dejar de estudiar y comprender una parte del mundo, sino que tendría un importantísimo alcance cualitativo: prescindir de uno de los elementos que más ayudan a comprender la singularidades y particularidades de cada cultura.
Por lo que se refiere a la cultura occidental, podríamos decir en términos metafóricos que ésta se ha configurado por Jerusalén. Atenas y Roma ${ }^{12}$. Esto no debe sorprendernos. La cultura es una producción y creación humana; el hombre ha actuado siempre movido por saberes orientadores de la acción: la religión, la ética y la política, el derecho. Estos distintos saberes prácticos han marcado los qués, los paraqués y los porqués de las personas y, por ello, han determinado las culturas humanas. Junto a la cultura de la alianza (religión) están la cultura del contrato (derecho) y la cultura de la vida común (ética y política). De todos estos saberes sobre el espíritu, ha sido la religión la que más ha marcado el rumbo y la idiosincrasia de cada cultura.

Es más, parece bastante claro que son las tradiciones religiosas distintas las que más diferencias provocan entre las culturas. En muchas ocasiones, es el desconocimiento o ignorancia de esas tradiciones lo que provoca grandes desencuentros entre aquéllas. La historia nos muestra que esto ha sido así; probablemente lo será cada día más en nuestro mundo interdependiente. Por ello no parece aventurado afirmar que sólo podrá haber diálogo intercultural si existe diálogo interreligioso. Si no se puede comprender Occidente sin llegar a entender mínimamente el judeo-cristianismo, tampoco se puede llegar a percibir la cultura de la India, con su sociedad tan jerarquizada, si se prescinde de toda referencia al hinduismo, o la cultura árabe y del Magreb, si prescindimos absolutamente del islamismo.

Esta exigencia de saber, de vivir juntos, de conocer al otro, no sólo afecta a estadistas, políticos, diplomáticos, empresarios que exportan a esos países etc., sino a todo ciudadano. Una ciudadanía activamente tolerante y respetuosa ante la inmigración no es viable, si se le priva de la posibilidad de llegar a entender lo culturalmente otro. El hecho religioso, en cuanto tal, debe ser estudiado para poder comprender la relevancia que el mismo ha tenido en la historia de la humanidad. De la misma forma, cada tradición religiosa debería ser mínimamente conocida para poder entender muchos de los fundamentos de cada cultura y de cada uno de los que forman parte de la misma.

Históricamente ha existido una relación circular entre filosofía, religión y derecho, y la misma ha conformado lo que hoy en día constituye la humanidad. Por todo ello, resulta imprescindible conocer el pensamiento filosófico y las

12 Cfr. HABERMAs, J., (2001), Israel o Atenas. Ensayos sobre religión, teología y racionalidad, Madrid, Trotta, que ha vuelto a poner de manifiesto cómo la filosofía griega y la religión judeo-cristiana han conformado la cultura occidental. 
tradiciones religiosas para conocer la cultura. También, indudablemente, es preciso conocer la historia de los hechos, y no sólo del pensamiento filosófico o político, para conocer el presente. Nuestra historia, la de cada sociedad, la de cada grupo humano y la de cada institución nos ayuda a entender lo que hoy somos. Prescindir de la historia, del pasado, es bloquear la comprensión del presente. En definitiva, el estudio del hecho religioso y de las diferentes tradiciones religiosas, de la filosofía y de la historia resulta imprescindible para conocer la cultura en general y cada cultura en particular. Prescindir de la educación escolar sobre el hecho religioso nos llevaría a considerar exclusivamente la racionalidad instrumental.

\section{2. ¿Qué consecuencias tiene una educación sin referencias religiosas?}

Esta reducción escolar conllevaría, en breve tiempo, una reducción antropológica y axiológica. Lo éticamente aceptable sería, simplemente, lo que en cada momento fuese científica y técnicamente posible, ya que no tendríamos a mano otras categorías para valorar las acciones a emprender. La experimentación y la experiencia sensible serían las que determinan la eticidad de las conductas: para ser bastaría experimentar y sentir. Lo bueno sería lo que provocase situaciones placenteras o supusiese avances sociales próximos, en términos medibles, en la productividad, en el cálculo de vida cuantitativa, etc.

Ésta es la sociedad que pretenden el nihilismo y el emotivismo fragmentario postmoderno. La mayor enfermedad de nuestros días es la falta de pasión por la verdad. Este clima difuso induce a muchos a rehuir la fatiga de hacerse cargo de la realidad y del entusiasmo que exige lo verdadero, abandonándose al disfrute de lo inmediato, en el tiempo, en el espacio, en el yo. Nuestro actual clima cultural nos aleja de la búsqueda de nuestra razón de ser (cómo hemos construido lo que somos), de nuestra razón de esperar (qué ha de venir) y de nuestra razón de amar (qué debemos hacer por nosotros, por los otros cercanos, pero también por todos los que constituimos una humanidad solidariamente unida en un mismo destino). Los valores podrán incluso ser proclamados retóricamente y respetados desde una tolerancia pasiva e irresponsable carente de nervio, pueden llegar a ser simples disfraces para ocultar una inquietante ausencia de significados. En esta noche del mundo no quisiéramos que triunfasen la indiferencia, el olvido y la pérdida de pasión por el ser humano. Por ello seguimos apostando por una educación escolar en la que tengan cabida las preguntas por el sentido de la vida, los saberes sobre el alma, la cultura de la memoria, la solidaridad que brota del amor: lo que nos ha hecho y nos sigue haciendo humanos. La religión, el hecho religioso, forman parte de esa cultura. Si privásemos a la mirada sobre lo real de lo religioso, en nuestra visión ya no se reconocería el rostro humano, quizá tan sólo su máscara ${ }^{13}$.

En relación intrínseca con los saberes filosóficos sobre el comportamiento humano y sobre la vida común, sobre el acontecer histórico y su memoria, cada tradición religiosa, aporta respuestas, no exclusivamente racionales, pero tampoco exentas de racionalidad, ante las grandes preguntas de la humanidad; y nos ofrece, además, un cuerpo de valores, asumidos por convicción, que se convierten en categorías necesarias para situarse en el mundo.

\subsection{La función de la enseñanza de la religión en la educación}

Si se quiere hacer realidad todo esto, el estudio del hecho religioso debe estar presente en el itinerario escolar junto a otras disciplinas, al mismo nivel que éstas, aunque con sus propios objetivos. No basta, sin embargo, con el conocimiento general sobre el hecho religioso. Es conveniente además una formación más específica en la tradición de una confesión religiosa concreta. Claro que este último itinerario educativo no puede ser único en una sociedad religiosamente plural: por eso hay que ofrecer un abanico de posibilidades para que el alumno opte. Pero, ¿qué es lo que aporta al proceso educativo la formación en las enseñanzas de una confesión religiosa concreta?

Además, cada tradición religiosa ofrece, en primer lugar, una respuesta a las grandes preguntas de cada hombre: el sentido de la vida y de la muerte, del sufrimiento y del dolor, de lo qué se puede esperar, del origen del universo, etc. No se trata de una respuesta científica, sino más bien experiencial y, en algún modo, también racional. Pero es una racionalidad distinta de la racionalidad positivista y empirista, aunque no menos válida, ya que el hombre necesita respuestas, sobre el origen último de todo y el para qué final de todo, que no siempre la ciencia empírica puede ofrecer. Si la ciencia empírica no da respuestas a estas preguntas, otros saberes humanos sí las ofrecen, al menos en parte, y estos saberes deben ser conocidos. Cada tradición religiosa ha ofrecido normas de conducta, individuales y sociales. Detrás de cada religión concreta existe una moral, qué marca pautas sobre lo qué está bien o está mal, lo que debe o no debe hacerse. Esta moral dimana de la experiencia religiosa de algunas personas, lo que conocemos como revelación.

13 Nos hemos inspirado, incluso transcribiendo literalmente algún párrafo, en la introducción de Bruno ForTE, (2002), de La esencia del cristianismo, Salamanca, Sígueme. 
Es justo reconocer que hay quienes con honestidad y conciencia crítica se oponen a las religiones, en sus manifestaciones y en sus exigencias, por todo lo que han tenido de deshumanizadoras. No se puede negar que bajo el nombre de lo religioso se han agazapado muchos intentos de destrucción o de represión de lo humano y parece justo que haya quienes tengan una seria y fundada prevención ante cualquier enseñanza sobre la religión. Ante tal carga negativa, antigua y reciente, ¿no sería mejor excluir cualquier contacto escolar con algo que no siempre ha contribuido al desarrollo de la persona? Es evidente que ése no es nuestro punto de vista, pero hemos de reconocer que quienes defienden esa posición no siempre lo hacen desde la manipulación de los datos o la visceralidad emotiva, sino desde una profunda honestidad. Quede claro nuestro respeto absoluto a todas las personas, y nuestra consideración amigable ante quienes, desde el agnosticismo, la increencia, o incluso la indiferencia, no comparten nuestros planteamientos. Precisamente porque creemos en ellos y en la posibilidad de un diálogo compartido brindamos nuestras razones, pero también porque un diálogo no sería posible si no creyésemos de entrada que su postura es muchas veces honesta y queremos descubrir su parte de verdad.

Para nosotros, también con sus sombras que conocemos y reconocemos, la religión es un hecho humano positivo que no puede ser ignorado ni menospreciado. Al contrario, creemos que una buena educación sobre lo religioso puede ayudar a que aparezcan y se desarrollen las mejores calidades de la religión como factor decisivo para la emancipación y la humanización de la sociedad. Nos parece muy acertada aquella expresión de Kant de que no hay nada más peligroso para el hombre que dejar la religión en minoría de edad ${ }^{14}$. Por el contrario, si apostamos por una ilustración y humanización de la religión, caminamos hacia un reconocimiento de posibilidades escondidas de humanidad y hacia una ilustración de la cultura. Ésa es nuestra apuesta: ilustrar la religión escolarizando la enseñanza de la religión, e ilustrar la escuela abriéndola a una consideración integral de la naturaleza humana.

Hoy en día nos encontramos también con la posibilidad de la ética cívica, aunque ésta requiere de importantes consensos a los que se llega muy lentamente. La ética cívica, que podemos identificar con la denominada ética de mínimos, se ha desarrollado principalmente en nuestro ámbito occidental, aten-

14 "He tratado del punto principal de la llustración, a saber, la emancipación de los hombres de su merecida tutela, en especial por lo que se refiere a cuestiones de religión...; esa tutela religiosa es, entre todas, la más funesta y deshonrosa”, en KAnT, I., (1941), Contestación a la pregunta ¿qué es la ilustración?, 1784, según la traducción de Eugenio Imaz, México. diendo sobre todo a las bases de la convivencia social. En este sentido, ayuda a plantear un horizonte debajo del cual no podemos hablar de humanidad: el horizonte de los derechos humanos, de la dignidad de la persona.

La ética de cada persona parece confiarse más bien al ámbito de la exclusiva privacidad. Pero el hombre necesita también modelos y valores para la realización personal, necesita, en última instancia, unos valores y principios que le orienten en su vida como persona, y no sólo en su quehacer como ciudadano. Cada una de las diferentes confesiones religiosas ofrece una concepción antropológica concreta que cristaliza en una serie de valores, principios y normas que orientan la acción. Son las que, desde una perspectiva filosófica racional, han venido a denominarse éticas de máximos. Pero éstas nunca son generalizables, en tanto que sus presupuestos antropológicos y sus normas de conducta sólo son compartidos por grupos limitados; tampoco han sido suficientemente consensuadas, ya que se asumen por convicción. Estas éticas de máximos son muy importantes, y no sólo para dar sentido a la vida de cada uno, sino también para contribuir al avance y desarrollo de la ética de mínimos vigente en la sociedad, que es fruto del consenso de todas ellas a través del diálogo y la confrontación. Entendemos, no obstante, que los ritmos de las distintas éticas de máximos y de la ética de mínimos sean distintos: las primeras se apoyan en la convicción, mientras que ésta última lo hace en el consenso.

Educar en este doble nivel ético, sabiendo distinguir lo que son las convicciones profundas que orientan la vida personal y lo que son principios éticos para una convivencia estable y pacífica, no es tarea fácil, pero es de gran trascendencia para el equilibrio personal y social de nuestro mundo: en el fondo se trata de buscar una postura que esté igualmente distante del fundamentalismo (frecuentemente religioso) y del relativismo ético.

Las modalidades académicas (áreas, asignaturas, disciplinas, ...) confesionales sobre el hecho religioso deben ofrecer en la escuela sus explicaciones fundamentadas sobre el mundo y el hombre, y mostrar sus normas de conducta. No deben en cambio entrar en planteamientos catequéticos. Es decir, deben dejarse de lado las experiencias personales y grupales de la fe. El contenido experiencial de la fe se desarrolla fundamentalmente a través del compromiso comunitario, de la oración y de la liturgia. En la educación escolar sólo debe desarrollarse lo que se puede evaluar desde criterios escolares: el grado de conocimiento de las verdades confesionales, la capacidad de asimilación intelectual de sus contenidos y las habilidades necesarias para la misma, la comprensión de los valores y actitudes que van unidas a esas verdades. 
Este conocimiento del hecho religioso en general y de cada tradición religiosa particular contribuirá a impedir el auge de los dogmatismos y de los integrismos. Si el ser humano necesita asumir por convicción determinados valores y verdades, al mismo tiempo debe tener la suficiente perspectiva y apertura de miras, para poder dialogar críticamente con los mismos. Sólo asî no se desemboca en indeseables fundamentalismos.

\section{Los principios constitucionales de la educación escolar}

En las líneas anteriores hemos concluido que una enseñanza cultural de la religión es deseable para la religión y para la escuela, para una religión que sea ilustrada, civilizada, que no tenga el riesgo de vivir «asilvestrada", y para una escuela que no sea unilateral, reductora, opaca a la realidad, manipuladora del sentido de lo humano, por ignorancia o malevolencia. A continuación trataremos de desentrañar qué dice nuestra Constitución a este propósito, y en qué medida la enseñanza de la religión debe ser escolar porque es esencial para una asimilación crítica de la cultura.

Nuestra Constitución de 1978 afrontó abiertamente esta problemática y dio una respuesta que, en lo esencial, sigue siendo válida. Esta solución lo ha sido durante 25 años precisamente por su amplitud, pero ésa puede ser también una fuente de debilidad. Porque la Constitución permite diferentes lecturas. De hecho -y hemos intentado mostrarlo- en 25 años y con tres mayorías parlamentarias ha dado lugar a tres formas de interpretarla. La UCD optó por un equilibrio respetuoso de la pluralidad recientemente reconocida (carácter académico, opcionalidad entre Religión y Ética); el PSOE subrayó, la particularidad de la ERE como derecho de la persona, recortando su carácter académico y colocándola en una posición de debilidad y de pura opcionalidad; el PP ha intentado subrayar el carácter escolar de la ERE integrándola en el currículo básico de los alumnos y haciéndola común a todos, desde la pluralidad de accesos: aconfesional para unos, confesional y plural para otros.

Ante estas diferentes lecturas -cada una de las cuales ha privilegiado un polo y ha ocultado una problemática-, vamos a exponer los que creemos son principios básicos de nuestra Constitución, antes de hacer algunas propuestas abiertas al diálogo en el seno de la comunidad educativa y en el debate público que la sociedad española debe realizar sobre este tema ${ }^{15}$.

15 Sobre algunos de los aspectos que siguen, en nuestra revista hemos publicado dos artículos, a los que nos remitimos: J. M. MARGENAT (1996) "La enseñanza de la religión: un debate euro-

\subsection{Principios de integralidad y de pluralidad}

Dos principios educativos constitucionales, complementarios y no opuestos entre sí, concurren a formar la cultura constitucional sobre la enseñanza escolar de la religión y deben conformar la voluntad del legislador. Los llamaremos, de forma breve, principio de integralidad y principio de pluralidad. Una asignatura Sociedad Cultura y Religión, obligatoria, como establece la LOCE, parecía coherente con el a. 27.2 de la Constitución (educación integral, a. 2.2.a, de LOCE) y con el a. 27.3 de la Constitución (educación plural, a. 2.2.b, de LOCE), en cuanto posibilita la integralidad y la pluralidad, a las que deben contribuir las enseñanzas obligatorias y comunes.

La cuestión central discutida es si la obligatoriedad de Sociedad Cultura y Religión forma parte de la regulación necesaria para la integralidad y para la pluralidad y por que ${ }^{-16}$. Parece indiscutible que los centros de titularidad pública están obligados a ofrecer las enseñanzas confesionales de la Religión, como ya reconocía la LOGSE (1990) en su disposición adicional segunda. Tampoco la actual ministra de Educación lo ha negado en ningún momento. Es discutible, sin embargo, si todos los alumnos están obligados a elegir alguna modalidad de la misma (confesional o no confesional). El obligar a elegir entre una yotra opción de desarrollo curricular puede derivar de dos supuestos: para contribuir a la formación integral del alumno dentro de las finalidades educativas de la escuela, o para apoyar positivamente al ejercicio efectivo del derecho a la educación religiosa (consiguiendo un cierto equilibrio organizativo pedagógico entre todos los alumnos). Dicho de otra manera: podemos llegar al principio de pluralidad desde el principio de integralidad o desde la cooperación positiva.

La integralidad de la educación de unos alumnos ¿puede implicar la obligatoriedad de una enseñanza para los otros alumnos? Si para la educación integral de unos alumnos es muy importante la enseñanza escolar de la religión, ¿puede obligarse a ella a todos? (lo que un exministro socialista formuló provocativamente: "¿puede alguien obligarme a mí a jugar al fútbol porque

peo": Revista Fomento Social 51, 55-82 y J. M. MARGENAT (2003) "La enseñanza de la religión en la nueva legislación": Revista Fomento Social 58, 365-376.

16 La LOCE, en la disposición adicional $2^{3}$, párrafo 1, parece afirmarlo taxativamente: "El área o asignatura de Sociedad, Cultura y Religión comprenderá dos opciones de desarrollo: una de carácter confesional, acorde con las confesión por la que opten los padres o, en su caso, los alumnos, (...); otra, de carácter no confesional. Ambas opciones serán de oferta obligatoria por los Centros, debiendo elegir los alumnos una de ellas”; la LOGSE, en 1990, decía: «oferta obligatoria para los centros y de carácter voluntario para los alumnos". 
otros quieran ir a misa?"). Sólo si se logra mostrar educativamente que para todos es importante, y aún necesaria, una enseñanza escolar de la religión, podríamos hablar de una integralidad que exige la obligatoriedad. Urge que el Parlamento realice este debate y defina esta cuestión: la asignatura o área de Sociedad, Cultura y Religión, ¿es necesaria para conseguir los objetivos educativos de la LODE y de la LOGSE que desarrollan el mandato constitucional (a. 27.2, integralidad), o es sólo necesaria para que algunos alumnos consigan desarrollar el mandato constitucional de una educación conforme a los propios valores y creencias ( $a$. 27.3, pluralidad desde la cooperación positiva del Estado con las confesiones)? El debate habrá de mantenerse en el terreno constitucional y estrictamente educativo y evitar los argumentos confesionales o ideológico-partidistas.

La ERE contribuye, dentro del área o asignatura de Sociedad Cultura y Religión y en el cuadro de las finalidades de la escuela ${ }^{17}$, a la formación integral de los alumnos desde el patrimonio cultural y desde la ciudadanía. Sólo de esa premisa se deriva la obligatoriedad de la elección entre esa área o asignatura confesional u otra opción de desarrollo ${ }^{18}$ aconfesional, aunque con los mismos objetivos en ambas alternativas. En ese caso la ERE deberá demostrar dos cosas: que por medio suyo se alcanzan los objetivos comunes y que sólo gracias a Sociedad Cultura y Religión, en cualquiera de sus opciones, pueden cumplirse todos los objetivos necesarios para una educación integral. Desde esta concepción deriva un tipo de ERE claramente curricular, estructurada y formulada según los principios y las opciones del diseño curricular común de los alumnos y según sus opciones de fondo y de método (cf. LOGSE art. 4.1 $)^{19}$. Esta orientación tiene una importancia muy grande, pues

17 Las finalidades educativas vienen definidas en los arts. 2.a, 2.b, 2.f. y, por extensión, a los otros fines: 2.c., 2.d, 2.e y 2.g; 4.a, 4.b; 6.a, 6.c de la LODE (1985) y arts. 1.1 y 2.3.a de la LOGSE (1990).

18 Según el término empleado por la LOCE, que nos parece acertado.

19 La formulación utilizada en la LOCE supuso un gran avance, como nunca hasta ahora se había expresado un documento oficial estatal, al decir que "las enseñanzas comunes ... han de proponer ... una educación que contribuya al desarrollo integral de todas las capacidades, ... así como los valores que deberán servir de referencia para la formación integral de los alumnos" y que, dentro de ellas, "las enseñanzas de Sociedad, Cultura y Religión, correspondientes a las opciones confesional y no confesional, se desarrollarán con estricto respeto a la Constitución española. Los objetivos y contenidos generales se establecen en respeto a la Constitución española. Los objetivos y contenidos generales se establecen en
este real decreto, sin perjuicio de la competencia correspondiente para la determinación del este real decreto, sin perjuicio de la competencia correspondiente para la determinación del currículo de la opción confesional". Conviene destacar las tres afirmaciones más explícitas e no cabrá cualquier ERE, sino sólo aquella -como la ya prevista en el citado documento Orientaciones del episcopado español de junio de 1979-que se desarrolle de acuerdo con un claro carácter escolar. Habrá, pues, que excluir toda forma de catequesis, formación doctrinal o meramente moral y lo que generalmente se denomina acción evangelizadora o pastoral. Es cierto que eso no impide considerar a la ERE, como a la educación en general, en un proyecto de pastoral o acción evangelizadora de conjunto, pero es claro que ésa es otra cuestión.

La ERE, integrada en el currículo básico, tiene que tener un carácter plenamente escolar formativo, cultural y crítico y desarrollarse dentro de las finalidades de la escuela. Esa ERE, "acorde con la confesión por la que opten los padres o, en su caso los alumnos" (LOCE, disp. adic. 2 $2^{\underline{a}}, 1$, y Constitución a. 27.3), en el caso de la ERE católica, responderá de su carácter confesional por la razón de la elección de los padres (o, en su caso, alumnos), por la garantía del profesorado encargado (tema muy complejo, y no menos importante, al que habría que dedicar otro comentario complementario) y por la confesionalidad de la orientación educativa, pero no dejará de ser escolar y plenamente curricular, dentro de su carácter opcional. De esta claridad conceptual derivan consecuencias inequívocas para la adecuada comprensión de la misión del profesorado, incluido su sistema de selección, nombramiento y eventual cese.

constitucionales de la autoridad estatal para definir el currículo básico, y no de un principio particular, se incluyen en el currículo por iniciativa del legislador y no para satisfacer un derecho particular de unos ciudadanos; (2) los objetivos y contenidos de SCR son comunes para todos y en un primer nivel de concreción curricular los fija la autoridad educativa para todos y en un pres la propia modulación de una u otra opción de desarrollo la que exija que intervengan unas la prrasina u otras instancias, por ejesto para las ensenanzas confosion respeto a la Constitución, esta afirmaciôn tiene un alcance sin precedentes, que nunca se había hecho, con un valor insospechado tanto para la ERE confesional católica, con más años de práctica de convivencia constitucional, como para la ERE de otras confesiones, cristianas y otras, con mucho menos tiempo de implantaciôn escolar en el sistema educativo democrático. Conviene asimismo indicar un problema que se ha abierto con esta perspectiva: ¿será siempre SCR crítica ante el hecho religioso?, o ¿pueden aparecer dos desplazamientos en ese inicial planteamiento crítico?: una tergiversación o prejuicio claramente antirreligioso, o una justificación criptoconfesional. 


\subsection{El principio de colaboración positiva}

Pero, ciertamente, cabría otra forma de argumentar. Para el ejercicio positivo del derecho a practicar la propia religión y ser formado en ella ${ }^{20}$, los poderes públicos han de colaborar positivamente con las confesiones que materializan este derecho y han de apoyar el ejercicio del mismo. El Estado español no es un Estado constitucionalmente laico (ni menos un Estado militantemente laicista), sino un Estado aconfesional. El Estado aconfesional no es neutral en relación con el hecho religioso, sino que su actuación está necesariamente informada por el principio de cooperación positiva con aquel hecho religioso, como sostienen tanto la Constitución como la Ley de libertad religiosa: "Los poderes públicos tendrán en cuenta las creencias religiosas de la sociedad española y mantendrán las consiguientes relaciones de cooperación..." (Constitución, a. $16.3)^{21}$. Esta forma de argumentar no parte tanto de las finalidades de la escuela ( lo que hemos denominado "curricularidad objetiva"), cuanto de la formación de los alumnos desde su propia creencia ("curricularidad subjetiva").

Consecuentemente con esta norma constitucional, el Estado debe promover $y$ proteger el derecho de los ciudadanos particulares a la educación religiosa que ellos demanden y ejercer cierta discriminación positiva en su favor. El problema es que no está claro el límite de dicha discriminación positiva, pues junto a éstos tiene a otros ciudadanos a quienes ha de proteger y a quienes no puede someter a una situación de obligación para garantizar el derecho de los primeros. El efectivo desarrollo del principio de integralidad (Constitución, a. 27.2) y de respeto a la educación según las convicciones de las familias (Constitución, a. 27.3) no puede quedarse en un principio teórico, sólo enunciado, sino que debe realizarse en la práctica con la colaboración positiva de las confesiones (Constitución, a. 16.3). Algún grado de apoyo mayor cabe para los que ejercen el derecho a elegir la formación religiosa conforme a sus creencias, pero no cualquier forma de apoyo. La exigencia de una obligatoriedad para todos sólo es aceptable en la lógica de la curricularidad objetiva (de acuerdo con las finalidades de la escuela), mientras que en la lógica de la curricularidad subjetiva sólo caben medidas de apoyo efectivo pero sin llegar a una obligatoriedad impuesta a todos. Si dicha obligatoriedad se argumentase

20 Cfr. Constitución, a. 16.1; Ley Orgánica de Libertad Religiosa, 7/80, de 5-7-1980, aa. 1.1, 2.1.a, 2.1.c, 2.2 y 2.3, y disposiciones antes citadas de la LODE y de la LOGSE.

${ }^{21}$ En la Ley de Libertad religiosa se dice: "Para la aplicación real y efectiva de estos derechos, los poderes públicos adoptarán las medidas necesarias para facilitar (...) la formación religiosa en centros docentes públicos" (Ley 7/80 de Libertad religiosa, a. 2.3) (o se percibiese) como condición para que una parte de los alumnos tenga enseñanza religiosa a costa de imponérsela a los que no la quieren ni la piden, suscitaría un gran rechazo.

\section{Nuestras propuestas para el diálogo sobre la ERE}

Creemos que es posible y deseable conseguir una solución duradera, consensuada y socialmente sostenible. Esta solución debe ser pactada políticamente $y$, a ser posible, formalizada en una norma legal estable, al abrigo de cambios gubernativos. La perspectiva en que nos situamos, pasa, por tanto, por la renuncia a posiciones confrontadas en exceso, por no decir extremas, y por la exclusión de planteamientos estrictamente partidistas, por legítimos que pudieran ser, o consideraciones sólo confesionales. Partimos de la base de que todos pueden ganar mucho si todos aceptan perder algo. Así saldrá ganando la sociedad española en su conjunto.

En concreto, en la Iglesia católica deberían flexibilizarse ciertas posturas que cabría calificar de maximalistas. La solución que se adopte debe ser plenamente escolar y compatible con el Estado constitucional no confesional. Las soluciones basadas, exclusivamente, en el Derecho concordatario tienen un difícil futuro. Porque un tema como éste debe fundamentarse en los derechos de las personas, no en la negociación de las instituciones. La Iglesia tiene unas competencias reales en la materia, pero su ejercicio ha de ser acorde con la naturaleza y autonomía de la escuela y con el carácter no confesional del Estado. Los objetivos fijados en los Acuerdos de 1979 eran fácilmente aceptados entonces, pero ahora distan mucho de lo que la sociedad española percibe como necesario para el bien común. La revisión de los Acuerdos entre la Santa Sede y el Estado español deberían incluirse en esta agenda política, para buscar una regulación jurídica adecuada a la nuevas realidades sociales y culturales del comienzo de este siglo. Y esta revisión obligaría a otros planteamientos pastorales complementarios por parte de la Iglesia para responder mejor a su misión en este nuevo contexto social, pero esa es una cuestión en la no podemos entrar aquí.

Los partidos, a su vez, tanto los de izquierda como los de derecha, deben renunciar a aprovecharse del rédito electoral que tiene defender posiciones utilitarias. Por eso proponemos firmemente, desde el principio, que se concluya en un pacto escolar sobre la ERE. Los sectores ideológicos de la izquierda o afines deben también renunciar a un dogmatismo excluyente en su concep- 
ción de la escuela. A nadie podemos exigir que deje de defender sus legítimas posiciones, pero creemos que unos y otros deben renunciar a las posiciones irreconciliables que han acabado haciendo de ésta una de las pocas cuestiones que, tristemente, todos enarbolan como seña de identidad y que sólo sirve para la confrontación.

Por último, partimos de la necesidad, que amplios sectores sociales y profesionales perciben, de que exista continuidad en la política educativa en este punto, por conflictivo que sea. Creemos que deberíamos intentarlo por la misma razón que los ciudadanos valoran que exista desde 1993 continuidad y estabilidad en la política económica. Nuestra sociedad tiene derecho, por razones tan profundas y exigentes como las económicas, a que las opciones de fondo en educación estén, en líneas tan fundamentales como ésta, libres de los indeseados efectos de los sucesivos y previsibles vaivenes de la política. Ahora queremos presentar el resultado de las reflexiones que preceden, ya largas, en forma de afirmaciones o propuestas que sirvan para el diálogo intelectual y para el debate público.

\subsection{Razones y formas de la presencia escolar de la ERE}

1. La ERE está y debe seguir estando presente en la escuela por razones culturales, con una legitimidad escolar propia, y no por razones confesionales. La ERE debe integrarse en el cuadro de las finalidades educativas de la escuela, como una materia ordinaria más, sin más excepciones que las que sean imprescindibles para las opciones de desarrollo confesional por ese mismo carácter.

2. Nos inclinamos por esta solución porque es la que da una respuesta mejor a los desafios sociales, porque es las que articula mejor los tres principios que hemos citado (integralidad, pluralidad, cooperación) y porque ofrece la mejor integración en el horizonte europeo, desde la historia propia española. Junto a la educación cultural de las diferentes confesiones con acuerdos con el Estado (confesional y específica para los creyentes o para quienes la soliciten), habrá una educación cultural de la religión no exclusivamente confesional, con itinerarios específicos para la educación cultural confesional de las diferentes religiones.

3. Esta solución se inserta en el modelo cultural predominante en España (cooperación escolar entre el Estado y la Iglesia; en nuestro contexto actual debe hablarse de todas las confesiones religiosas reconocidas), aunque asuma

\section{algunos elementos del modelo de plena integración.}

4. Esta solución, nueva en la historia educativa de España, debe permitir una profunda elaboración de la educación cívica común, de la ética de mínimos, de aquel patrimonio cultural que es común para todos los ciudadanos (cultura religiosa) y de la educación constitucional. Estos contenidos educativos deben tener su propia autonomía, sin que queden subrogadas todas estas dimensiones en las diferentes opciones de desarrollo curricular de la ERE.

\subsection{Soluciones insuficientes}

5. Descartamos asimismo otras tres posibilidades, que tienen apoyos y que pueden justificarse razonablemente, pero que, a nuestro juicio, resuelven peor la demanda social, la demanda de la escuela, y la adecuación a nuestra propia tradición histórico-educativa y jurídico-política.

a) En primer lugar rechazamos la posibilidad de que la ERE se convierta es una educación eclesial en la escuela pública no confesional, marcadamente confesional y catequética. No creemos que esa solución, que defienden teóricamente, pero sobre todo en la práctica, algunas instancias eclesiásticas, sea el mejor modelo ya que dejaría de ser escolar.

b) Asimismo, rechazamos la alternativa de una educación laicista, totalmente excluyente del hecho religioso de la escuela, por las razones antedichas. Rechazamos, pues, la evolución de la actual regulación (1990, 1994, 1995) en el sentido de una marginación escolar de la ERE y de su configuración extremadamente confesional.

c) Por último rechazamos que la ERE quede reducida a una educación intercultural e interreligiosa (no confesional) del hecho religioso, sin necesidad de itinerarios específicos confesionales para cada una de las religiones. Rechazamos, por tanto, una ERE sólo cultural.

6. Ninguna de estas tres propuestas es, a priori, compatible con nuestro actual ordenamiento jurídico; por otra parte, han de ser excluidas por la naturaleza misma de la escuela y del Estado.

\subsection{Papel del Estado}

7. El Estado puede asumir plenamente, aunque no en exclusiva, todo lo relativo a la ERE, tanto en la modalidad no confesional o estudio del hecho 
religioso, como en las modalidades confesionales de las distintas tradiciones religiosas. El Estado puede y debe reservarse el derecho de no aceptar determinados contenidos que puedan atentar contra la dignidad de la persona en los términos que la legislación estatal expresa positivamente para tutela de los derechos fundamentales, así como limitar el ejercicio de aquellas actividades educativas que pudiesen ser contrarias a una educación escolar inspirada en los valores constitucionales y en los principios de la ética cívica.

8. El Estado precisa de la colaboración de las confesiones para las asignaturas ${ }^{22}$ de contenido confesional. En esta materia el Estado no goza de competencia jurídica ni técnica para determinar qué contenidos son los propios de estas disciplinas. No parece apropiado que, desde la institucionalidad administrativa del Estado pueda determinarse qué "verdades" y normas morales de cada confesión deben ser explicadas en el aula. Son las propias confesiones las que deben determinar cuáles son sus verdades fundamentales y las normas morales que prescriben, dándoles a cada una de ellas la significación que estimen convenientes, dentro del respeto a la Constitución y al carácter propio de la ERE.

9. El Estado cooperará ofreciendo espacios en la escuela pública para impartir estas disciplinas de contenido confesional y financiará la nómina de los profesores, al igual que ocurre con los de cualquier otra disciplina académica. Las confesiones, por otro lado, deben aceptar la adscripción y distribución que de estos profesores se realice en las escuelas públicas, con idénticos criterios y procedimientos a los del resto del claustro.

\subsection{Papel de las confesiones religiosas}

10. Las confesiones sítienen en cambio algo que decirrespecto a las personas que resultan apropiadas para desarrollar estas funciones docentes, pero sin que esto se convierta, en cada caso, en una valoración particular y parcial de la autoridad eclesiástica competente por razón del territorio. De ser así, cabría llegar a situaciones que, al menos, pueden ser difícilmente comprensibles para la ciudadanía en general. El profesorado de religión requiere, al igual que cualquier otro profesor, una estabilidad jurídica y unos procedimientos objetivos para su selección, su valoración y su eventual remoción.

22 Para mayor agilidad usamos indistintamente las expresiones área, asignatura, materias o disciplina, aunque técnicamente no sean sinónimos; por otra parte, también haremos equivalente modalidad y opción de desarrollo curricular.
11. Los docentes de ERE han de estar integrados de forma coherente con el resto del claustro. De esta forma, no se producirían estridencias ni situaciones poco comprensibles en las estructuras organizativas de la escuela pública. Sería conveniente que los profesores se integrasen en la estructura de cuerpos de funcionarios del Estado, tras contar con el beneplácito de las correspondientes confesiones.

12. Sólo por motivos bien fundados, valorados en comisiones mixtas, de ámbito autonómico o nacional, por autoridades religiosas y funcionarios de las consejerías de educación, se podría apartar a los profesores de sus tareas. Es posible, con determinadas condiciones, un estatuto de funcionariado para el profesorado de religión, para lo que, en nuestro contexto europeo, contamos con las soluciones adoptadas en países como Alemania y, más recientemente, Italia.

13. Desde estos planteamientos se integrarían las asignaturas de contenido confesional en los esquemas propios de la escuela. Las disciplinas tendrían unos contenidos objetivos, por lo que podrían ser plenamente evaluables.

\subsection{Aspectos jurídicos de la propuesta}

14. Entendemos que estas soluciones responden plenamente a nuestros principales marcos de referencia.

a) Por una parte, desde una perspectiva más genérica, a las exigencias que derivan de la Declaración Universal de los Derechos Humanos: "La educación tendrá por objeto el pleno desarrollo de la personalidad humana y el fortalecimiento del respeto a los derechos humanos y a las libertades fundamentales; favorecerá la comprensión, la tolerancia y la amistad entre todas las naciones y todos los grupos étnicos o religiosos. (...). Los padres tendrán derecho preferente a escoger el tipo de educación que habrá de darse a sus hijos” (a. 26.2). Estas exigencias se han integrado en nuestro ordenamiento constitucional (Constitución española, a. 27.2 y 27.3).

b) Por otra parte, y desde una perspectiva más específica entendemos que no habría excesivas dificultades para incardinarlas en el espíritu de los Acuerdos entre el Estado español y la Iglesia católica, en particular en el Acuerdo sobre Enseñanza y Asuntos Culturales de 1979 y, llegado su día, a la revisión de los mismos. 


\subsection{Necesidad de consenso socia}

15. Esta definición del principio que fundamenta la ERE en el sistema educativo reclama un consenso social básico y un acuerdo parlamentario fundamental. Sin la deliberación de la sociedad civil y el acuerdo entre derecha e izquierda la bandera retórica de la ERE seguirá izada. Sin deliberación y consenso democráticos no es posible resolver este problema. El Gobierno anterior propuso una buena solución, pero ésta sólo será realmente estable cuando sea una solución aceptable para la inmensa mayoría parlamentaria, al menos para las dos grandes fuerzas del arco parlamentario. El Gobierno actual y el partido que lo sostiene deben abrir un debate de interpretación constitucional sobre el futuro de esta Ley. A esto se ha comprometido la ministra San Segundo. En el curso 2004-2005 se realizará el debate social y el año siguiente se tramitará la Ley que podría entrar en funcionamiento en el curso 2006-2007.

16. La izquierda debería reconocer que éste es un buen camino de solución y contribuir al desarrollo y a la interpretación constitucional de la LOCE y de los decretos que la desarrollan. Pasado el intenso período electoral entre la primavera de 2003 y junio de 2004, hemos llegado a un tiempo más propicio para la regulación de la ERE de acuerdo con el espíritu y con la letra de la Constitución. A esto parece apuntar el camino iniciado por la ministra de Educación y a esto quiere contribuir este editorial.

\subsection{Procesos inmediatos}

17. Nuestra propuesta prevé que en la escuela pública española, en las etapas entre los 3 y los 18 años (prácticamente generalizadas, aunque aún no todas obligatorias), se desarrolle una educación cultural de la religión no exclusivamente confesional, con itinerarios específicos para la educación cultural confesional de las diferentes religiones. La clave sería la complementariedad de los dos principios concurrentes (integralidad y pluralidad) junto con el de colaboración con las realidades significativas religiosas (=las iglesias) para la aplicación de estos principios.

18. La LOCE y los RR. DD. de 27-6-2003 que desarrollan las enseñanzas comunes, actualmente en suspensión, dieron un giro a la regulación de la ERE en continuidad con la propuesta del último Gobierno socialista de Felipe González. Proponemos con carácter experimental lo siguiente: a) Que a partir del curso 2005-2006 se aplique la LOCE con el desarrollo previsto en los Decretos citados de Suárez Pertierra, al menos para los cursos $3^{\circ}$ y $4^{\circ}$ de ESO, y $1^{\circ}$ de bachillerato (14-17 años).

b) Que en el curso 2008-2009 se haga una evaluación de la aplicación de la LOCE en ese tramo: si ésta resultase positiva podría generalizarse a toda la ESO y al Bachillerato, es decir al tramo de 12-18 años.

19. Los planteamientos que contiene la LOCE podrían contribuir a resolver el problema, si se consiguiese un consenso duradero entre los dos principales partidos y entre las fuerzas sociales y culturales que se sitúan en sus áreas. Este consenso debería resolverse en tres momentos: debate público, pacto cívico y pacto político parlamentario a través de una Ley de la enseñanza de las religiones, que no esté sometida a la variación de partidos gobernantes, previsible en todo sistema parlamentario. La ERE de los españoles debería quedar regulada preferencial y definitivamente por lo que se afirma en nuestra Constitución y en el bloque de la constitucionalidad, en los Pactos internacionales y, sobre todo, en el propio desarrollo legislativo español que se ha propuesto.

20. Ese sería el momento, el curso 2008-2009, de revisar el Acuerdo con la Santa Sede sobre enseñanza. La nueva formulación del mismo debería ser muy básica, basarse en el principio de colaboración y establecer cauces orgánicos para ésta en los asuntos educativos y culturales, además de regular algunas situaciones que puedan estar pendientes inter potestates.

\section{Conclusión}

Quedan muchas cuestiones pendientes. La decisión sobre en qué momento del proceso educativo del alumno deben impartirse estas disciplinas, la duración de las mismas, etc. Se trata de un debate pedagógico, que requiere también atención y dedicación. No obstante, no entraremos en el mismo. La formación de los profesores funcionarios en su capacidad docente para impartirenseñanza no confesional (hecho religioso) y confesional (católica, etc.) de la religión y la ordenación definitiva del contrato laboral de los profesores de ERE confesional con el Estado, asumiendo éste las responsabilidades únicas en cuanto a su contratación y despido, con todas las obligaciones subsiguientes, son otro conjunto de cuestiones a tratar más detenidamente. También se encuentra en ese caso el papel que las iglesias o confesiones tendrían en la selección y el derecho a conceder el nihil obstat a quienes hubiesen de desempeñar la enseñanza de la religión de una confesión determinada. 
Sería sumamente pretencioso querer en este editorial dar respuesta a todos los problemas que se plantean en un tema tan complejo como éste. Nuestro objetivo último era mucho más modesto: tan sólo pretendíamos afirmar la necesidad de una solución fundamentada, consensuada y cooperativa. Desde esta perspectiva hemos pretendido participar en ese debate, exponiendo nuestros fundamentos y convicciones y proponiendo algunas soluciones concretas. Se trata, tan sólo, de actuar en coherencia con lo que creemos tener derecho a demandar: que los poderes públicos, las autoridades religiosas de todas las confesiones y la sociedad en general hagan unas propuestas fundamentadas y abiertas al debate, $y$, por ello, a posibles soluciones consensuadas. Nosotros hemos querido aportar, para ello, nuestro punto de vista.

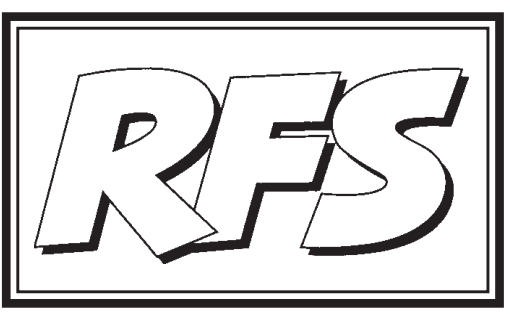

Revista de Fomento Social, 59 (2004), 277-301

\section{Asia en el mundo del siglo XXI}

\author{
João GUIMARÃES
}

(Palabras clave: Futuro de Asia, Milagro asiático, Recursos naturales, Pobreza. KEY WORDS: FUtURE OF ASIA, ASIAN MIRACLE, NATURAL RESOURCES, POVERTY)

\section{Introducción}

Es difícil exagerar la importancia y el significado de un tema como es "Asia en el mundo del siglo XXI". Como espero quede claro en las páginas que siguen, el futuro del mundo en el que vivimos y en el que vivirán nuestros hijos se juega hoy, y seguirá jugándose durante bastante tiempo, en Asia más que en el resto del planeta.

Hablar o escribir en términos generales sobre el Asia del siglo XXI no es tarea fácil. En primer lugar, por el inmenso número de variables que afectan

1 Institute of Social Studies, La Haya, Holanda. E-mail: guimaraes@iss.nl. El autor agradece al profesor Francisco Amador, de ETEA, la invitación para participar en la jornada de estudio y reflexión sobre el tema de "Asia en el mundo del siglo XXI", que tuvo lugar en ETEA el 30 de abril de 2004. La ponencia presentada en esa jornada está en el origen del presente artículo.

\section{ESTUDIOS}

